\title{
Ćwierć wieku polskich badań nad grami wideo
}

Maria B. Garda, Stanisław Krawczyk 


\section{Ćwierć wieku polskich badań nad grami wideo}

Maria B. Garda, Stanisław Krawczyk

TEKSTY DRUGIE 2017, NR 3, S. 69-86

DOI: $10.18318 / \mathrm{td} .2017 .3 .5$

Drzedmiotem artykułu jest złożona historia polskich badań nad grami wideo. Badania gier (podobnie jak inne dziedziny nauki) nie mogą obejść się bez autorefleksji, a więc także wiedzy o własnej historii i stanie obecnym. W anglojęzycznym obiegu naukowym problematykę tę poruszano niekiedy w starszych pracach ${ }^{1}$, ale w ostatnim czasie jej obecność staje się bardziej dostrzegalna. Przykładem tego są badania nad tematyką publikacji ${ }^{2}$ oraz zainteresowaniami i afiliacjami samych badaczy ${ }^{3}$.W niektórych wypadkach - dość rzadkich - autorefleksja ma

1 H. Lowood Game studies now, history of science then, "Games and Culture" 2006 No. 1.

2 E. Melcer, T.-H. Nguyen, Z. Chen, A. Canossa, M.S. El-Nasr, K. Isbister Games Research Today: Analyzing the Academic Landscape 2000-2014, w: Proceedings of the 10th International Conference on the Foundations of Digital Games, 2015.

3 T. Quandt, J. Van Looy, J. Vogelgesang, M. Elson, J.D. Ivory, M. ConsaIvo, F. Mäyrä Digital games research: A survey study on an emerging field and its prevalent debates, "Journal of Communication” 2015 No. 6.

\section{Maria B. Garda}

- dr, kulturoznaw-

czyni, asystentka

w Zakładzie Mediów

Elektronicznych UŁ,

wiceprzewodnicząca

Polskiego Towarzy-

stwa Badania Gier,

redaktor naczelna

„Replay. The Polish

Journal of Game

Studies.'WWW:

mariabgarda.com.

Kontakt: mbgarda@

uni.lodz.pl

Stanisław Krawczyk

- doktorant w Instytucie Socjologii UW, sekretarz zarządu Polskiego Towarzystwa Badania Gier, asystent redaktora naczelnego w czasopiśmie "Homo Ludens". Kontakt: krawczykstanislaw@ gmail.com 
wyraźny rys krytyczny4. Niewiele jest jednak systematycznych analiz historycznego rozwoju badań nad grami, i to nawet w tak ważnych dla tej dziedziny krajach jak państwa nordyckie i Stany Zjednoczone ${ }^{5}$. Dość podobnie przedstawia się stan wiedzy o badaniach polskich. Dotychczasowe opracowania ${ }^{6}$ analizują ich historyczny wymiar fragmentarycznie, dlatego też przyjrzymy się zainteresowaniu grami w różnych obiegach naukowych. Rozważymy także kwestie terminologiczne i sformułujemy następującą tezę: dzięli procesom instytucjonalizacji i umiędzynarodowienia w polskich badaniach nad grami wyłonił się nurt badawczy bliski anglojęzycznej dziedzinie game studies, dla którego najbardziej właściwą rodzimą nazwą jest "groznawstwo".

Przedstawiając zarys historii polskich badań nad grami wideo, korzystamy z różnych źródeł. Są to istniejące już publikacje naukowe, wywiady z trzema spośród najdłużej aktywnych naukowo badaczy, 21 zestawów odpowiedzi na ankietę przeprowadzoną w lipcu wśród polskich badaczy i badaczek, a także dane zastane: katalogi biblioteczne, programy konferencyjne, uczelniane strony internetowe itp. Czerpiemy również z wiedzy, którą nabyliśmy, uczestnicząc w życiu polskiego środowiska groznawczego. Z kolei w części poświęconej publikacjom korzystamy z własnego przeglądu zawartości czasopism naukowych i z baz danych zawierających informacje na ich temat.

\section{Wczesna historia badania gier wideo w Polsce}

Początki rodzimej refleksji akademickiej nad ludyczną sferą kultury sięgają co najmniej międzywojnia ${ }^{7}$. Zainteresowanie grami przybrało jednak na sile

4 Zob. M. Filiciak, P. Sterczewski, B. Schweiger, P. Frelik, S. Krawczyk Trybalizm, pominięcia, uprzedzenia. Badania gier z perspektywy krytycznej, „Kultura Współczesna” 2016 nr 2.

5 Zob. S. Deterding The Pyrrhic victory of game studies: Assessing the past, present, and future of interdisciplinary game research, "Games and Culture" 2016 No. 1.

6 A. Surdyk Status naukowy ludologii. Przyczynek do dyskusji, „Homo Ludens” 2009 nr 1; A. Surdyk Badania kultury popularnej w zakresie nowych mediów w kraju i na świecie na przykładzie organizacji ludologicznych, w: Literatura i kultura popularna. Badania i metody, red. A. Gemra, A. Mazurkiewicz, Pracownia Literatury i Kultury Popularnej oraz Nowych Mediów, Wrocław 2014; S. Krawczyk Perspektywa krytyczna w polskich badaniach gier cyfrowych. Analiza publikacji, „Kultura Współczesna” 2016 nr 2.

7 E. Piasecki Zabawy i gry ruchowe dzieci i młodzieży: ze źródeł dziejowych i ludoznawczych, przeważnie rodzimych, i z tradycyi ustnej, wyd. 2, Książnica Polska Towarzystwa Nauczycieli Szkół Średnich i Wyższych, Lwów 1919; F. Znaniecki Ludzie teraźniejsi a cywilizacja przyszłości, Książnica Atlas, Lwów-Warszawa 1934. 
dopiero w latach 90. XX wieku, zapewne przede wszystkim w odpowiedzi na rozwój elektronicznej rozrywki. Równocześnie warto pamiętać, że zanim gry komputerowe stały się w Polsce elementem kultury popularnej, miały swoje miejsce w ośrodkach badawczych. Uznawane obecnie za pierwszą polską grę komputerową Kótko i krzyżyk (Miś, 1960) ${ }^{8}$ powstało w Zakładzie Aparatów Matematycznych Państwowej Akademii Nauk. Z kolei od lat 70. działała Szkoła Symulacji Systemów Gospodarczych ${ }^{9}$, której członkowie już w dekadzie Gierka prowadzili projekty badawcze, które można określić jako symulacyjne gry komputerowe - uruchamiane na maszynach takich jak polska seria komputerów Odra. Związany z tym środowiskiem Tadeusz Pszczołowski definiował zabawę na podstawie prac Huizingi, a grę - nawiązując do teorii gier i organizacji10 ${ }^{10}$. Dzisiaj polscy badacze wywodzący się z tego nurtu badań (m.in. z Akademii Leona Koźmińskiego) działają w strukturach stowarzyszenia International Simulation and Gaming Association, które rozwinęło się równolegle z czasopismem „Simulation \& Gaming”"1.

Pierwszy rodzimy tekst naukowy poruszający problematykę gier wideo, do którego udało nam się dotrzeć, to publikacja autorstwa Ryszarda Ciarki wydana w 1991 roku $^{12}$ (a więc jedenaście lat po - uznawanej za pionierską w skali międzynarodowej - pracy Thomasa W. Malone'a $\left.{ }^{13}\right)$. Reprezentuje ona ten nurt badań nad grami cyfrowymi, który wywodzi się z filmoznawczej tradycji studiów nad kulturą audiowizualną, i stawia liczne pytania o przyszłość medium filmowego w obliczu rozwoju nowego zjawiska, jakim są gry komputerowe. Sam Ciarka nie odnosi się do innych badań nad grami, natomiast pozostali prekursorzy polskiego groznawstwa najczęściej odwoływali się do

8 B. Kluska, współpr. M. Rozwadowski Bajty polskie, wyd. 2.o popr. i uzup., nakład własny, Sosnowiec 2014, s. 7-8.

9 Zob. K.K. Nowak Szkoła Symulacji Systemów Gospodarczych (1978-2010) - historia i dorobek, „Management and Business Administration. Central Europe” $2014 \mathrm{nr} 2$.

T. Pszczołowski Mała encyklopedia prakseologii i teorii organizacji, Ossolineum, Wrocław 1978, s. 74. Omówienie definicji: M. Wardaszko Wykorzystanie symulacyjnych gier decyzyjnych w nauczaniu zarządzania [praca doktorska], Akademia Leona Koźmińskiego, Warszawa 2013, s. 38. D. Crookall The founding of modern simulation/gaming: S\&G and ISAGA four decades on „ „Simulation and Gaming" 2012 No. 1.

R. Ciarka Śmierć kina, w: Sztuka na wysokości oczu. Film i antropologia, red. Z. Benedyktowicz, D. Palczewska, T. Rutkowska, Instytut Sztuki PAN, Warszawa 1991.

13 T.W. Malone What makes things fun to learn? A study of intrinsically motivating computer games, Xerox Palo Alto Research Center Technical Report No. CIS-7 (SSL-80-11), 1980. 
klasycznych studiów nad grą i zabawą, a więc do Johana Huizingi (Homo ludens, oryg. 1938, tłum. polskie 1967) i Rogera Caillois (Gry i ludzie, oryg. 1958, tłum. pol. $1997^{14}$ ).

Jedną z pierwszych polskich konferencji akademickich, w trakcie których szerzej poruszano tematykę gier wideo, była sesja naukowa zorganizowana przez Marylę Hopfinger - „Od fotografii do rzeczywistości wirtualnej” (11-13 grudnia 1995 roku). W tomie pokonferencyjnym znajdziemy tekst Zbigniewa Wałaszewskiego, który analizuje doświadczenie rozgrywki w tytułach takich jak Doom (id Software, 1993) i zestawia je z doświadczeniem odbioru innych mediów ${ }^{15}$. Hopfinger była w późniejszym okresie promotorką lub recenzentką kilku prac doktorskich o grach wideo i grach fabularnych (RPG). Warto w tym miejscu zwrócić uwagę na przychylność opiekunów naukowych i - szerzej - całego kulturoznawczego środowiska akademickiego dla badań nowego zjawiska ${ }^{16}$. Młodzi badacze gier nie trafiali w Polsce na ostracyzm, z którym zetknęła się Mary Ann Buckles. Autorka jednej z najwcześniejszych prac doktorskich $\mathrm{w}$ dziedzinie przyszłych game studies ${ }^{17}$, poświęconej grom przygodowym, tuż po swojej obronie postanowiła na zawsze opuścić świat akademicki ${ }^{18}$.

Nie tylko kulturoznawcy i badacze mediów interesowali się w Polsce grami. Czasopismo „Toruńskie Studia Dydaktyczne”, gdzie opublikowano wiele prac na temat wykorzystania komputerów w kształceniu, w 1995 roku zamieściło dwa teksty o edukacyjnym zastosowaniu gier wideo ${ }^{19}$. „Zeszyty Prasoznawcze" z 1996 roku zawierają tekst medioznawczy omawiający gry

14 Dla ścisłości, fragmenty prac Caillois były dostępne w języku polskim już od lat 70. XX wieku. Zob. R. Caillois Ludzie a gry izabawy, w: tegożŻywiołi ład, przeł. A. Tatarkiewicz, PIW, Warszawa 1973.

Z. Wałaszewski Niekończące się powtarzanie, nieskończoność powtórzenia, w: Od fotografii do rzeczywistości wirtualnej, red. M. Hopfinger, Wydawnictwo IBL PAN, Warszawa 1997.

Wątek ten pojawił się w naszych wywiadach z Piotrem Sitarskim (4 listopada 2015 roku) i Zbigniewem Wałaszewskim (5 grudnia 2015 roku).

M.A. Buckles Interactive fiction: The computer storygame «Adventure» [praca doktorska], UC San Diego 1985.

M. Erard 2 Decades Later; Let Down by Academia, Game Pioneer Changed Paths, "The New York Times" 06.03.2004.

M. Kikulska Walory dydaktyczne wybranych gier komputerowych, „Toruńskie Studia Dydaktyczne" 1995 nr 2; P. Piszkalski Możliwości wykorzystania gry komputerowejSIM CITY w edukacji dzieci klas młodszych , "Toruńskie Studia Dydaktyczne" 1995 nr 2. 
komputerowe w kontekście teorii Marshalla McLuhana ${ }^{20}$. Pod koniec dekady pojawiły się też akademickie artykuły pedagogiczne przedstawiające gry jako zagrożenie dla dzieci i młodzieży ${ }^{21}$ (krytyczne względem gier publikacje z dziedziny psychologii były nieco późniejsze ${ }^{22}$ ). Z kolei związany ze środowiskiem Polskiego Towarzystwa Cybernetycznego Andrzej Barczak opublikował podręcznik akademicki poświęcony komputerowym grom wojennym ${ }^{23}$.

W tym okresie zaczęły powstawać także prace magisterskie poświęcone grom wideo, jak praca Krzysztofa Arkuszewskiego o recepcji gry Quake (id Software, 1996) ${ }^{24}$. Dotarcie do innych opracowań naukowych z tego okresu stanowi istotne wyzwanie archiwistyczne, gdyż są to w dużej mierze teksty nieskatalogowane. Niemniej ich odnalezienie przysłuży się z pewnością badaniom historycznym - zarówno nad genezą i rozwojem groznawstwa, jak i nad historią recepcji gier wideo w Polsce.

\section{Pierwsza faza instytucjonalizacji}

Międzynarodowa konferencja „Challenge of Computer Games” (25-27 października 2002 roku), której głównym organizatorem był Piotr Sitarski, była pierwszym polskim wydarzeniem tego rodzaju. Wzięło w niej udział 19 prelegentów z kraju - na łącznie 46 uczestników z wielu państw, reprezentujących zarówno instytucje akademickie, jak i środowiska publicystów i twórców gier ${ }^{25}$. Choć konferencja była miejscem spotkania przyszłego środowiska naukowego, to okazała się niewykorzystaną szansą trwałego umiędzynarodowienia polskich badań gier, do czego przyczynił się brak publikacji

20 P. Płaneta Piekło McLuhana czy "elektroniczne ocalenie"? Gra komputerowa jako środek transmisji kultury, "Zeszyty Prasoznawcze" $1996 \mathrm{nr} 3 / 4$.

21 H. Noga Zagrożenie wolności człowieka przez programy komputerowe ,"Studia nad Rodziną" 1998 $\mathrm{nr} 2$; H. Noga Antywychowawcze aspekty gier komputerowych, "Paedagogia Christiana” $1999 \mathrm{nr} 1$.

I. Ulfik-Jaworska Czy gry komputerowe mogq być niebezpieczne?, "Wychowawca” 2002 nr 1; M. Braun-Gałkowska, I. Ulfik-Jaworska Zabawa w zabijanie. Oddziaływanie przemocy prezentowanej w mediach na psychikę dzieci, Wydawnictwo Archidiecezji Lubelskiej "Gaudium", Lublin 2002.

23 A. Barczak Komputerowe gry wojenne, Wydawnictwo Bellona, Warszawa 1996.

24 K. Arkuszewski Quake - fenomen społecznego odbioru gry komputerowej [praca magisterska], Uniwersytet Warszawski 1998. 
pokonferencyjnej. Na następną inicjatywę tej skali trzeba było poczekać ponad dekadę.

We wrześniu 2004 roku na Akademii Podlaskiej odbyła się pierwsza edycja cyklicznej konferencji „Inżynieria Gier Komputerowych”; wzięło w niej udział około 80 uczestników ${ }^{\mathbf{2 6}}$. W pierwszym tomie pokonferencyjnym można znaleźć tekst Marka Ostaszewskiego i Michała Rudnickiego, który omawia ewolucję gier cRPG i odwołuje się do prac Janet Murray ${ }^{27}$. Jest to jednak jeden z nielicznych przypadków, gdy autorzy publikacji IGK powołują się na humanistyczne lub społeczne badania gier (a te z kolei rzadko odnoszą się do informatyki). Być może z czasem to się zmieni, gdyż w ostatnich latach wykształciły się nowe przestrzenie komunikacji badaczy gier z dziedziny humanistyki, nauk ścisłych i uczelni artystycznych. Mamy tu na myśli konferencję "Game Industry Conference”, organizowaną od 2012 roku równolegle z Poznań Game Arena, a także „Conference on Game Innovations”, która odbyła się po raz pierwszy w Łodzi w 2016 roku.

Ważnym etapem instytucjonalizacji krajowych badań nad grami było powołanie Polskiego Towarzystwa Badania Gier w 2004 roku²8. Rok później w Poznaniu odbyła się pierwsza konferencja PTBG, w której wzięło udział ponad 120 osób ${ }^{29}$. Kolejne edycje odbywają się w rytmie rocznym aż do dziś, kontynuowane są również wydarzenia z cyklu „Inżynieria Gier Komputerowych”. W 2007 roku teksty powstałe po inicjalnej konferencji PTBG opublikowano w dwu tomach zbiorowych ${ }^{30}$, w roku 2008 szereg artykułów zamieszczono w piśmie „Homo Communicativus”, a w 2009 - w nowo utworzonym periodyku „Homo Ludens”. Periodyk ten, istniejący do dziś, był do 2014 roku jedynym społeczno-humanistycznym czasopismem o grach wydawanym w Polsce. Według naszych rachunków w latach 2009-2015 ukazały się w nim 54 artykuły o grach wideo (32\% ze 168 artykułów opublikowanych w tym czasie).

26 M. Ostaszewski, M. Rudnicki, A. Świtalska, A. Wojciechowska, J. Tchórzewski Wstęp, w: Inżynieria gier komputerowych, Wydawnictwo Akademii Podlaskiej, Siedlce 2004, S. 5.

M. Ostaszewski, M. Rudnicki Przyszłość fabularnych gier komputerowych, w: Inżynieria gier komputerowych. Historia powstania i rozwoju PTBG została już szczegółowo opisana w innych publikacjach. Zob. A. Surdyk Badania kultury popularnej...

29 A. Surdyk Wstęp, w: Kulturotwórcza funkcja gier. Gra jako medium, tekst i rytuał (tom 1), red. A. Surdyk, Wydawnictwo Naukowe UAM, Poznań 2007, s. 7.

30 Kulturotwórcza funkcja gier... (tom 1); Kulturotwórcza funkcja gier. Gra jako medium, tekst i rytuał (tom 2), red. A. Surdyk, J.Z. Szeja, Wydawnictwo Naukowe UAM, Poznań 2007. 


\section{Ludologia a groznawstwo}

Polskie Towarzystwo Badania Gier określa się jako „towarzystwo ludologiczne”. We wczesnym tekście programowym Augustyn Surdyk definiuje „ludologię" jako szeroko pojętą „naukę o grach”31, a więc w sposób bliski oryginalnej propozycji Gonzala Fraski, mówiącej o ludologii jako „dyscyplinie, która bada aktywności gry i zabawy"32. Espen Aarseth zauważa, że wprawdzie w ujęciu Fraski ludologia miała być dla gier tym, czym narratologia dla narracji, ale badacz ten nigdy nie sprecyzował metodologicznych czy też paradygmatycznych założeń ludologii ${ }^{33}$. Być może dlatego podejście to nie znalazło szerokiego zastosowania w dalszych anglojęzycznych badaniach nad grami. Zazwyczaj jest utożsamiane z nurtem badawczym żywym na przełomie wieków ${ }^{34}$ oraz ze specyficznym podejściem do badania gier skupionym na rozgrywce i mechanice. Aarseth podkreśla, że ludologia to nie dyscyplina ani paradygmat, ale przede wszystkim historycznie uwarunkowana krytyczna reakcja wobec prób zastosowania teorii literatury do badania gier ${ }^{35}$.

Tak zwany spór narratologów z ludologami nie miał swojego odpowiednika na gruncie polskim, jednak termin „ludologia” jako nazwa krajowych badań nad grami zyskał dużą popularność. Niemniej warto podkreślić, że nawet w połowie ubiegłej dekady termin ten stosowany był przez niektórych badaczy gier wideo wymiennie z określeniami takimi jak „teoria gier wideo"36 czy „poetyka zabawy"37, a więc o węższym znaczeniu niż proponowane przez Surdyka.

Motywacją, która przyświecała takiemu ujęciu ludologii przez twórców PTBG, było zapewne dążenie do inkluzywności, a więc interdyscyplinarnego badania gier - nie tylko w dziedzinie humanistyki i bez ograniczania

31 A. Surdyk Charakter i cele Polskiego Towarzystwa Badania Gier oraz perspektywy badań nad grami w Polsce, w: Kulturotwórcza funkcja gier... (tom 2)

G. Frasca Ludology meets narratology: similitude and differences between (video) games and narrative. „Parnasso" 1999 No. 3.

E. Aarseth Ludology, w: The Routledge companion to video game studies, Routledge, New YorkLondon 2014, s. 185.

Reprezentowanym przede wszystkim przez Markku Eskelinena, Gonzala Frascę i Jespera Juula. Mowa tu głównie o krytyce prac Brandy Laurel i Janet Murray przeprowadzonej przez Eskelinena (zob. M. Eskelinen The gaming situation, "Game Studies” 2001 No. 1). M. Filiciak Wirtualny plac zabaw. Gry sieciowe i przemiany kultury współczesnej, Wydawnictwa Akademickie i Profesjonalne, Warszawa 2006, s. 62.

37 J. Stasieńko Alien vs. Predator? Gry komputerowe a badania literackie, Wydawnictwo Naukowe Dolnośląskiej Szkoły Wyższej Edukacji TWP, Wrocław 2005, s. 12. 
zainteresowań do gier wideo. Ważną rolę wśród założycieli PTBG odegrali bowiem badacze zajmujący się grami niecyfrowymi, m.in. grami fabularnymi i zastosowaniem gier w edukacji.

Tak rozumiane pojęcie ludologii niewątpliwie odegrało istotną rolę w konsolidacji określonego środowiska naukowego. Sądzimy jednak, że na obecnym etapie rozwoju polskich badań nad grami potrzebna jest inna perspektywa, uwzględniająca dwukierunkowy rozwój tej dziedziny wiedzy (badania informatyczne $v s$ badania humanistyczno-społeczne) oraz bliższa stosowanemu dziś nazewnictwu anglojęzycznemu. Proponowany przez nas porządek terminologiczny (rysunek 1) rozróżnia trzy pojęcia: (1) „badania nad grami” lub "badania gier” to nazwa wszystkich badań akademickich związanych z grami, (2) "groznawstwo" - nazwa zinstytucjonalizowanych badań przyjmujących głównie perspektywę humanistyczną lub społeczną ${ }^{38}$, a (3) „ludologia” - nazwa badań skupionych na analizie gier pod względem formalnym. Groznawstwo koncentruje się przy tym zwykle na grach wideo i jest podstawową dyscypliną badającą ten rodzaj gier w ramach szeroko rozumianej humanistyki. Rzadziej w ramach groznawstwa prowadzone są badania poświęcone innym grom, a także badania w zakresie nauk ścisłych i technicznych.

Rysunek 1. Relacja między terminami: „badania nad grami”, "groznawstwo" i, „ludologia”.

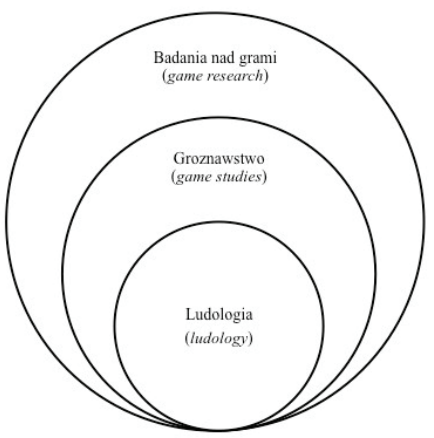

Źródło: opracowanie własne ${ }^{39}$

38 Według naszej wiedzy pojęcie to w znaczeniu fachowym pojawiło się po raz pierwszy w języku polskim w przekładzie artykułu Espena Aarsetha, gdzie tłumacz mówi o "groznawcy" (oryg. game scholar). Zob. E. Aarseth Badanie zabawy: metodologia analizy gier, przeł. M. Filiciak, w: Światy z pikseli. Antologia studiów nad grami komputerowymi, SWPS Academica, Warszawa 2010, s. 23.

Dziękujemy Michałowi Mochockiemu za dyskusję, która zainspirowała powyższy rysunek. 
Rozróżnienie pojęć game research i game studies pochodzi od Sebastiana Deterdinga ${ }^{40}$. Polski termin "groznawstwo" został utworzony analogicznie do nazw innych dyscyplin, takich jak „filmoznawstwo” (film studies) czy „medioznawstwo" (media studies) ${ }^{41}$. Wykorzystując go, pragniemy również zwrócić uwagę na to, że w rodzimych badaniach gier pojawił się nurt, który w coraz większym stopniu przypomina anglojęzyczną dyscyplinę game studies. Zbieżność z zagranicznym nazewnictwem nie jest więc celem samym w sobie, lecz odzwierciedla podobieństwo obu pól badawczych.

\section{Umiędzynarodowienie i dalsza instytucjonalizacja}

U progu drugiej dekady XXI wieku wielu współcześnie aktywnych badaczy i badaczek podjęło studia doktoranckie z myślą o realizowaniu tematów poświęconych wyłącznie grom wideo. Początek ich ścieżki naukowej wiąże się z powstaniem formalnych i nieformalnych zrzeszeń młodych naukowców. W 2011 roku powstały trzy tego rodzaju organizacje studencko-doktoranckie: Koło Naukowe Badaczy Gier przy Uniwersytecie Łódzkim, Koło Badaczy Popkultury Trickster przy Uniwersytecie Wrocławskim oraz nieformalna grupa badaczy Lvl.up związana z Uniwersytetem Jagiellońskim ${ }^{42}$. Środowiska skupione wokół tych inicjatyw zorganizowały w kolejnych latach wiele konferencji naukowych, niekiedy w całości poświęconych grom wideo. W 2015 roku odbyło się dziewięć konferencji podejmujących tę problematykę $e^{43}$, rozsianych po ośrodkach akademickich w całym kraju, a w większości z nich brało udział wielu doktorantów.

Na Uniwersytecie Łódzkim od 2013 roku odbywa się cykliczna konferencja młodych naukowców „Kultura Gier Komputerowych” (KGK). Referaty zaprezentowane na pierwszej edycji konferencji stały się podstawą otwierającego numeru „Replay. The Polish Journal of Game Studies”, jak dotąd jedynego polskiego czasopisma groznawczego skupionego na badaniu gier wideo. W ostatnich latach miejscem organizacji licznych konferencji jest

\footnotetext{
S. Deterding The Pyrrhic victory of game studies..., s. 3-12.

M.B. Garda Interaktywne fantasy. Gatunek w grach cyfrowych, Wydawnictwo UŁ, Łódź 2016, S. 15 .

Początkowo Sekcja Projektantów i Badaczy Gier Koła Naukowego Medioznawców UJ.

Szczegółowe informacje na ten temat są dostępne pod adresem http://tinylink.pl/25_lat_badan (adres alternatywny: http://goo.gl/auJzT9). Znajduje się tam baza danych, którą utworzyliśmy na potrzeby artykułu i którą zamierzamy regularnie uzupełniać.
} 
Uniwersytet Jagielloński; międzynarodową rangę miała druga edycja „Central and Eastern European Game Studies Conference” (CEEGS, 2015) oraz czwarta edycja "Games and Literary Theory" (GamesLit, 2016), a w 2017 roku uczelnia ta będzie organizatorem kolejnej ważnej konferencji groznawczej: „Philosophy of Computer Games”. Poza tym niezależny Ośrodek Badawczy Facta Ficta w Krakowie organizuje od 2015 roku cykliczną konferencję „Dyskursy Gier Wideo", a także wiele innych wydarzeń - niejednokrotnie o zasięgu ponadnarodowym - których tematyka obejmuje gry cyfrowe. Wreszcie we Wrocławiu na początku roku 2017 odbyło się seminarium "Matters of Construction”, a na grudzień tego roku zaplanowano konferencję „Generation BioWare: Story-Driven Games in Contemporary Humanities".

Krajowi badacze uczestniczą również w wydarzeniach zagranicznych. $\mathrm{Na}$ przykład na konferencji Digital Games Research Association i Foundation of Digital Games (DiGRA i FDG) w 2016 roku polska delegacja stanowiła prawdopodobnie najliczniejszą (14 osób) spośród reprezentacji narodowych. Oprócz tego znacząca część aktywnych badaczy odwołuje się do aktualnych publikacji anglojęzycznych, pojawiły się już także pierwsze artykuły rodzimych autorów w zagranicznych czasopismach groznawczych ${ }^{44}$. Ponadto niektóre rozwiązania organizacyjne krajowych edycji CEEGS i GamesLit oraz trzeciej edycji KGK (m.in. sposób oceny zgłoszeń) pokrywały się z zasadami przyjętymi na konferencjach DiGRA. Wszystko to świadczy o postępującej internacjonalizacji rodzimych badań nad grami, a także ich coraz mocniejszej pozycji w regionie Europy Środkowej i Wschodniej.

Ważnym krokiem w instytucjonalizacji dyscypliny jest chwila, kiedy staje się ona przedmiotem studiów uniwersyteckich ${ }^{45}, \mathrm{w}$ tym wypadku kształcących specjalistów w zakresie projektowania, teorii i krytyki gier wideo. Od roku 2010, kiedy to edukacja akademicka w tej dziedzinie ograniczała się niemal wyłącznie do uczelni politechnicznych ${ }^{46}$, powstaje coraz więcej humanistycznych kierunków

P. Frelik The Master's Digital Tools: Cognitive Capitalism and Non-Normative Gaming Practices, "Journal of Gaming and Virtual Worlds" 2016 No. 2; M. Garda, P. Grabarczyk Is Every Indie Game Independent? Towards the Concept of Independent Game, "Game Studies" 2016 No. 1; P. Sterczewski Replaying the lost battles: The experience of failure in Polish history-themed board games, "Kinephanos” 2016 No. 1; P. Sterczewski This Uprising of Mine: Game Conventions, Cultural Memory and Civilian Experience of War in Polish Games, "Game Studies" 2016 No. 2.

Zob. J. Stasieńko Cyberkulturoznawstwo - akademickie programy studiów z dziedziny nowych mediów i cyberkultury, „,Kultura i Historia” 2008 nr 2. 
i specjalności uwzględniających przedmioty groznawcze. Właśnie w 2010 roku na Uniwersytecie Jagiellońskim w ramach projektu Wiking ${ }^{47}$ współfinansowanego ze środków Unii Europejskiej uruchomiono specjalizację „Projektowanie gier wideo" skierowaną do studentów kulturoznawstwa (drugiego stopnia). Po zakończeniu projektu specjalność ta jest nadal realizowana na tamtejszym filmoznawstwie w ramach studiów magisterskich. Podobne kierunki i specjalności istnieją także na innych uczelniach, m.in. w Dolnośląskiej Szkole Wyższej we Wrocławiu, na Uniwersytecie Kazimierza Wielkiego w Bydgoszczy, Uniwersytecie Łódzkim, Uniwersytecie Marii Curie-Skłodowskiej w Lublinie, Uniwersytecie Opolskim czy Uniwersytecie Śląskim.

Rozwój instytucjonalny wiąże się również z powoływaniem nowych jednostek badawczych. W 2015 roku na Uniwersytecie Marie-Curie Skłodowskiej w Lublinie utworzono Centrum Badań Gier Wideo, w 2016 roku w Dolnośląskiej Szkole Wyższej we Wrocławiu powołano Centrum Badawczo-Projektowe Gier i Animacji „Digital Masters”, a w roku 2017 na Wydziale Polonistyki Uniwersytegu Jagiellońskiego powstał Ośrodek Badań Groznawczych. Zwiększa się też liczba samodzielnych pracowników naukowych, którzy mogą być promotorami i recenzentami groznawczych rozpraw doktorskich. Osoby, które uzyskały stopień doktora w pierwszej dekadzie XX wieku, coraz liczniej otrzymują habilitację, co w długoterminowej perspektywie może wpłynąć na wzrost liczby doktorantów. I wreszcie należy wskazać inicjatywy popularnonaukowe i publicystyczne, w jakich uczestniczą polscy groznawcy, takie jak blog Jawne Sny (2011) czy Grakademia (2012).

Nurt, który wyłonił się dzięki umiędzynarodowieniu oraz postępującej instytucjonalizacji rodzimych badań gier wideo - i w ramach którego oba procesy wciąż nabierają tempa - określamy mianem groznawstwa. Opisane tu przemiany nie zachodzą równomiernie w całym polu badawczym, jednak ich wpływ jest odczuwalny we wszystkich jego sektorach. Naszym zdaniem groznawstwo stało się dominującą częścią społecznych i humanistycznych badań nad grami w Polsce, a za kilka lat pojęcia groznawstwa i badania gier mogą okazać się wręcz synonimiczne.

\section{Analiza publikacji}

W tej części tekstu dokonamy ilościowej analizy dorobku polskich badań nad grami wideo. Wyraz „polskie” można tu rozumieć rozmaicie, jako że „uczeni

Strona internetowa projektu: http://www.gry-wideo.if.uj.edu.pl/ (22.11.2016). 
mogą być związani z określonym regionem na wiele sposobów - przez urodzenie, tradycję naukową, miejsce obecnego pobytu, zainteresowania akademickie, wykształcenie itd." ${ }^{48}$. W poniższej analizie uwzględniamy prace polskojęzyczne, a także anglojęzyczne teksty autorów reprezentujących polskie instytucje naukowe. Kryteria te są jednoznaczne i łatwe do zastosowania, chociaż mogą okazać się problematyczne w przyszłości, jeśli wzrośnie liczba obcokrajowców zatrudnionych w Polsce (np. w ramach projektów grantowych) oraz osób mówiących po polsku i mających polskie obywatelstwo, ale studiujących lub pracujących na zagranicznych uczelniach.

Podstawą analizy będzie przegląd krajowych czasopism naukowych. Opierając się na nich, mogliśmy stosunkowo łatwo dotrzeć do znacznej liczby publikacji, a zarazem zastosować możliwie ścisłe kryteria doboru danych ${ }^{49}$. Tworzenie listy czasopism rozpoczęliśmy od dwu periodyków groznawczych, „Homo Ludens" $i$ „Replay. The Polish Journal of Game Studies". Przejrzeliśmy również internetową bazę Arianta (w kategoriach: „kulturoznawstwo”, ,kultura fizyczna i sport”, ,dziennikarstwo i media”,,,pedagogika”, ,psychologia” i „psychologia społeczna”), aby upewnić się, że nie pominęliśmy żadnych czasopism specjalistycznych. Potem dodaliśmy do wykazu każdy znany nam periodyk naukowy, który zamieścił choć jeden artykuł o grach wideo, oraz sprawdziliśmy historię wszystkich czasopism z listy, przeglądając spisy treści numerów wydanych do 2015 roku i wynotowując publikacje o stosownej tematyce ${ }^{50}$. Zarówno tutaj, jak i w dalszej części analizy nie wzięliśmy pod uwagę roku 2016, gdyż w czasie powstawania tekstu nie były jeszcze dostępne publikacje wydane w listopadzie bądź grudniu albo antydatowane na ten rok.

Następnie przeszukaliśmy dwie internetowe bazy artykułów z czasopism polskich w systemie MAK (bazę dla lat 1996-2004 oraz bazę tekstów opublikowanych po 2004 roku), w roli zapytań wyszukiwawczych wykorzystując hasło przedmiotowe "gry komputerowe" oraz nazwiska autorów wszystkich

48 B. Liboriussen, P. Martin Regional Game Studies, "Game Studies” 2016 No. 1.

Dążąc do spełnienia tego wymogu, umożliwiamy czytelnikom prześledzenie procedury selekcyjnej i przybliżamy badanie do standardu intersubiektywnej sprawdzalności. Standard ten opisuje Sabina Cisek w artykule Metoda analizy i krytyki piśmiennictwa w nauce o informacji i bibliotekoznawstwie WXXI wieku („Przegląd Biblioteczny” 2010 nr 3, s. 278). Przywołana publikacja, będąca rodzajem instruktażu dla badaczy rekonstruujących stan wiedzy w różnych dziedzinach nauki, jest dla nas ważnym źródłem wskazań metodologicznych.

50 W wątpliwych wypadkach posiłkowaliśmy się streszczeniami lub pełnymi tekstami. Zdecydowana większość uwzględnionych tekstów to prace w całości poświęcone grom wideo; nieliczne wyjątki dotyczą ich tylko częściowo. 
znanych nam monografii. Dzięki temu zgromadziliśmy kolejne teksty i zlokalizowaliśmy blisko pół setki nierozpatrzonych dotąd czasopism, z których zdecydowana większość była reprezentowana tylko przez pojedynczą publikację. Uznając, że najprawdopodobniej nie są to periodyki istotne dla polskich badań nad grami cyfrowymi, postanowiliśmy dokładnie sprawdzić spisy treści jedynie takich pism, w których na tym etapie mogliśmy wskazać przynajmniej dwa teksty o grach wideo. W efekcie otrzymaliśmy dodatkową grupę artykułów i na niej zakończyliśmy zbieranie materiału badawczego.

Wszystkie te zabiegi pozwoliły na przygotowanie bazy danych, która stanowi podstawę poniższej analizy ${ }^{51}$. Zbiór ten gromadzi niemal wyłącznie artykuły z zakresu nauk humanistycznych i społecznych - publikacje informatyczne wydają się stanowić oddzielny obieg, podobnie jak w badaniach anglojęzycznych ${ }^{52}$, i na ich temat nie będziemy się wypowiadali.

Nasz korpus tekstowy liczy 257 artykułów napisanych przez 154 osoby (109 mężczyzn i 45 kobiet, czyli 71\% mężczyzn i 29\% kobiet; płeć określamy na podstawie brzmienia imion i nazwisk). Tylko $42 \mathrm{z}$ nich - około $27 \%-$ to autorzy lub współautorzy przynajmniej dwu publikacji wydanych w latach 1995-2015 (33 mężczyzn i 9 kobiet, a więc, odpowiednio, $79 \%$ i 21\%) ${ }^{53}$. Przyjmując takie szacunkowe kryterium zaangażowania, możemy stwierdzić, że aktywnych badaczy gier wideo w Polsce nigdy nie było wielu.

Wspomniane 42 osoby są autorami bądź współautorami 158 tekstów, tj. $61 \%$ wszystkich opublikowanych artykułów. W wielu wypadkach to również organizatorzy i uczestnicy specjalistycznych konferencji oraz aktywni członkowie formalnych i nieformalnych organizacji groznawczych. W październiku 2016 roku akademickie afiliacje członków tej grupy przedstawiały się następująco: 9 osób z Uniwersytetu Jagiellońskiego, 5 osób z Uniwersytetu Łódzkiego, 4 osoby nieafiliowane, po 3 osoby z Uniwersytetu Warszawskiego

51 Baza ta jest dostępna pod adresami http://tinylink.pl/25_lat_badan i http://goo.gl/au/zTg. Pominęliśmy w niej czasopismo "Ha!art", które w ostatnich latach publikowało liczne artykuły o grach wideo; ma ono bowiem charakter raczej kulturalny niż naukowy (nigdy nie figurowało w ministerialnym wykazie czasopism punktowanych, jego strona internetowa w czasie pisania tego tekstu nie zawierała informacji o recenzjach w systemie peer review etc.). day..., sekcja 5.1.

Gdybyśmy zamiast tego rozpatrzyli lata 2013-2015 - przypatrując się najnowszemu okresowi badań, a nie całej ich historii - analogiczna podgrupa liczyłaby 24 osoby spośród 86 (odsetek niemal taki sam jak poprzednio: 28\%). W gronie tym byłoby 17 mężczyzn i 7 kobiet (71\% i 29\%; proporcje nieznacznie bardziej wyrównane niż w latach 1995-2015). 
i Uniwersytetu im. Adama Mickiewicza, po 2 osoby z Uniwersytetu Marii Curie-Skłodowskiej i Uniwersytetu w Białymstoku, 2 osoby, których afiliacji nie udało się ustalić, oraz po 1 osobie z innych uczelni ${ }^{54}$. Z tej perspektywy można mówić o dwu grupach badawczych, w Krakowie i Łodzi. Pozostałe osoby należałoby uznać albo za wolnych strzelców (niekiedy współpracujących z powyższymi grupami), albo za członków grup, których aktywność do końca 2015 roku nie przełożyła się na publikację odpowiedniej liczby artykułów.

Wykres 1 pokazuje, jak zmieniała się liczba tekstów publikowanych w kolejnych latach. Przez pewien czas było to najwyżej kilka prac rocznie, ale po 2007 roku stopniowo ustabilizowała się tendencja wzrostowa, a rok 2015 okazał się szczególnie obfity (co czwarty artykuł z ostatniego dwudziestolecia został wydany właśnie w tym roku).

Wykres 1. Liczba artykułów opublikowanych w poszczególnych latach.

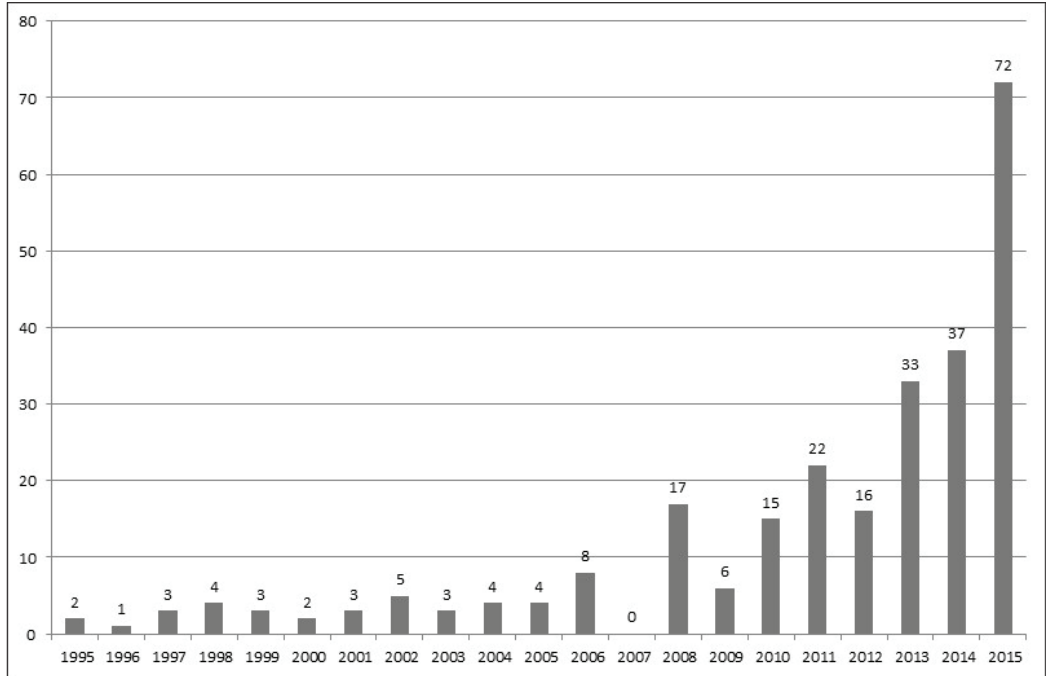

Źródło: opracowanie własne.

54 Mówiąc ściślej: z Akademii Pedagogiki Specjalnej, Dolnośląskiej Szkoły Wyższej, Politechniki Poznańskiej, Szkoły Głównej Handlowej, Uniwersytetu Mikołaja Kopernika, Uniwersytetu Opolskiego, Uniwersytetu Pedagogicznego im. KEN w Krakowie, Uniwersytetu SWPS, Uniwersytetu Szczecińskiego, Uniwersytetu Śląskiego, Uniwersytetu Warmińsko-Mazurskiego i Uniwersytetu Wrocławskiego. Nie sprawdzaliśmy, jak zmieniała się afiliacja instytucjonalna poszczególnych osób przed październikiem 2016 roku, dlatego nasze wnioski w tym miejscu dotyczą tylko stanu obecnego. 
Do zbliżonych wniosków prowadzi analiza listy czasopism, które w całej swojej historii opublikowały przynajmniej dwa artykuły o grach wideo (stosowne dane w podziale na lata podsumowuje wykres 2). Oprócz 2 periodyków poświęconych badaniu gier były to 4 pisma literaturoznawcze, 6 kulturoznawczych, 4 medioznawcze, 2 pedagogiczne i 2 filmoznawcze, tudzież 3 czasopisma z innych dziedzin. To zróżnicowanie jest jednak domeną ostatniej dekady, a zwłaszcza ostatnich paru lat. Do 2005 roku artykuły o grach wideo można było znaleźć tylko w 1 lub 2 periodykach rocznie, a w następnych czterech latach wyłącznie rok 2007 stanowił wyraźny wyjątek od dotychczasowej reguły. Dopiero w odniesieniu do lat 2010-2015 można mówić o konsekwentnie utrzymującej się różnorodności: średnio około 8 czasopism na rok, w kilku obiegach dyscyplinarnych.

Wykres 2. Liczba pism, które w danym roku opublikowały przynajmniej dwa artykuły o grach wideo.

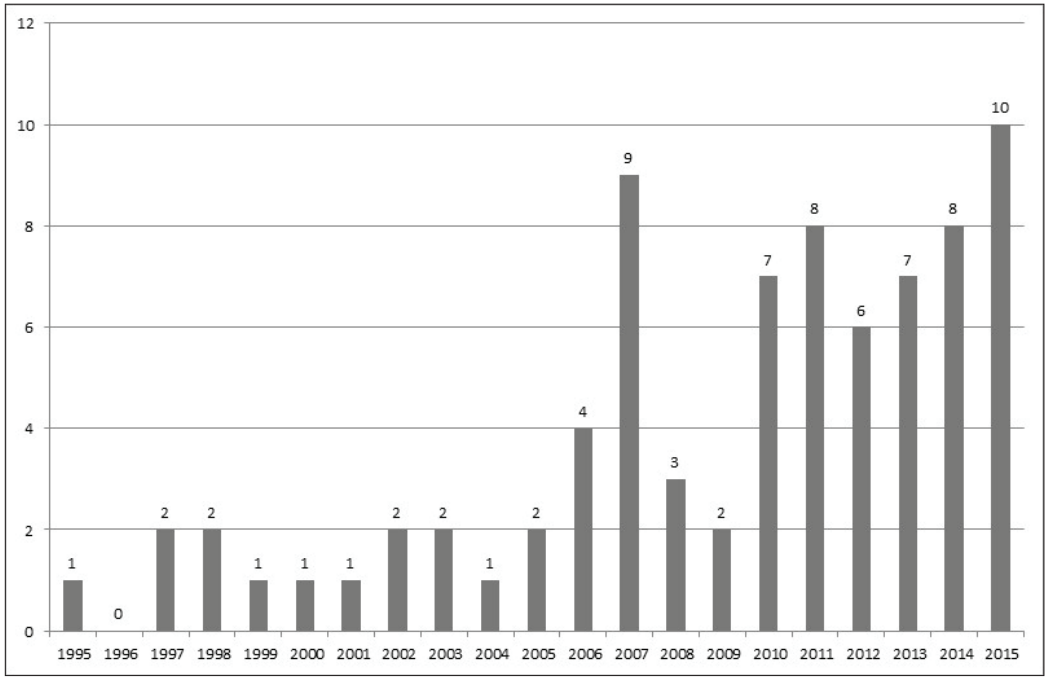

Żródło: opracowanie własne.

Pod względem liczby zamieszczanych tekstów początkowo wyróżniała się „Kultura Popularna” (9 artykułów wydanych do 2006 roku), a później przede wszystkim „Homo Ludens” oraz w dalszej kolejności „Ekrany” i „Replay" (odpowiednio, 54, 23 i 15 artykułów w latach 2009-2015). Odsetek prac publikowanych w piśmie „Homo Ludens” pozostawał znaczący przez cały czas jego istnienia (w 2009 roku było to $75 \%$ wszystkich zebranych tekstów, 
w 2010 - 36\%, w 2011 - 32\%, w 2012 - 25\%, w 2013 - 50\%, w 2014 - 17\%, w 2015 - 26\%), ale od roku 2014 pozycja periodyku wydaje się słabnąć. Trzeba przy tym zauważyć, że w ostatnich latach pojawiły się nie tylko liczne numery rozmaitych czasopism zawierające pojedyncze prace o grach wideo, lecz także kilka wydań obejmujących większą liczbę tego rodzaju publikacji. Były to dwa numery groznawczego periodyku "Replay” (2014 i 2015) oraz wydania tematyczne „Czasu Kultury” i „Wielogłosu” (2015), a jeśli wykroczymy poza materiał badawczy rozpatrywany systematycznie w tej części artykułu, to również dwa numery tematyczne magazynu kulturalno-artystycznego „Ha!art” (2014 i 2015) oraz specjalne wydania „Kultury Współczesnej” (2016) i obecnie „Tekstów Drugich".

Do przedstawionych wyżej zmian niewątpliwie przyczyniło się wiele procesów, w tym ogólny wzrost liczby polskich periodyków oraz ich znaczenia w ocenie parametryzacyjnej jednostek naukowych. Tutaj chcielibyśmy zwrócić uwagę na rosnące zainteresowanie grami wideo wśród krajowych literaturoznawców, o którym świadczy powyższy wykaz numerów specjalnych. Pod względem instytucjonalnym głównym ośrodkiem tego zainteresowania jest Wydział Polonistyki Uniwersytetu Jagiellońskiego.

Oprócz artykułów obieg groznawczy w Polsce tworzą również monografie, tomy zbiorowe, a w pewnym sensie także tłumaczenia. Te pierwsze rozkładają się dość równomiernie na lata 2002-2016 i niemal wszystkie są opublikowanymi wersjami prac doktorskich, ewentualnie książkami habilitacyjnymi. Poza 17 monografiami odszukaliśmy cztery tomy zbiorowe i pięć książek tłumaczonych z języka angielskiego. Jeden z tomów zbiorowych został wydany w 2007 roku po konferencji PTBG, a pozostałe siedem pozycji rozłożyło się równomiernie na lata 2010-2016 55 .

Przeprowadzona analiza pokazuje, że badania gier wideo są niewielkim wycinkiem polskiego pola naukowego, który ma dwa kluczowe ośrodki: w Krakowie i Łodzi. Lata 2010-2015 były jednak okresem dość konsekwentnego wzrostu liczby publikacji w tej dziedzinie, zwiększonej różnorodności czasopism zamieszczających teksty o grach cyfrowych, a także

55 Dane dotyczące stopni naukowych zawiera prowadzona przez Ośrodek Przetwarzania Informacji baza danych Ludzie nauki (jest ona częścią serwisu internetowego "Nauka Polska”). Wiadomości o monografiach, tomach zbiorowych i przekładach, tak jaki inne podobne informacje, zamieściliśmy we wspominanej już własnej bazie danych. Nie uwzględniamy w tym miejscu książek z zakresu informatyki, gdyż wydają się one stanowić obieg całkowicie odrębny od groznawczego (tymczasem artykuły czy referaty nawiązujące do tej dziedziny można okazjonalnie znaleźć w numerach czasopism społeczno-humanistycznych i programach konferencji). 
równomiernego wydawania tomów zbiorowych bądź przekładów prac anglojęzycznych. Oznacza to, że przyspieszenie procesu instytucjonalizacji szło w parze z rosnącą aktywnością publikacyjną polskich badaczy (i w mniejszym stopniu - badaczek). Jedynie w obiegu monograficznym nie widać podobnej dynamiki, lecz regularność wydawniczą na przestrzeni ostatnich kilkunastu lat.

\section{Zakończenie}

Badanie gier wideo cieszy się w Polsce rosnącym zainteresowaniem naukowców. Jak zauważa Deterding w odniesieniu do badań anglojęzycznych, „podczas gdy badania nad grami [game research] rozwijają się i różnicują, to w ich ramach groznawstwo [game studies] coraz bardziej zlewa się w relatywnie zamkniętą społeczność, składającą się z badaczy z obszaru humanistyki [...], których łączy jednorodna kultura epistemiczna"56. Wydaje się, że w ostatnich latach zbliżone zjawisko zachodzi w Polsce (mimo nieco innych uwarunkowań). Oczywiście, około czterdzieściorga zaangażowanych autorów przez ćwierć wieku - to wciąż niedużo. Historia rodzimych badań nad grami nie jest linearna, czego dowodzi chociażby przypadek wczesnych prób ich umiędzynarodowienia i konferencji „Challenge of Computer Games”.W tak małym polu badawczym łatwo mogą się pojawić nowe czynniki, których rolę dzisiaj trudno ocenić. Na przykład może się okazać, że z powodu barier w rozwoju kariery akademickiej jedynie mała część aktywnych obecnie doktorantów pozostanie w rodzimym obiegu naukowym, a bardziej doświadczeni groznawcy mogą z czasem ograniczyć zainteresowanie grami (niektórzy z nich zresztą już po obronie pracy doktorskiej skierowali uwagę na inne zjawiska). Jeżeli jednak utrzymają się tendencje, które przedstawiliśmy we fragmencie dotyczącym najnowszej historii badań, to zapewne polskie groznawstwo zachowa dynamikę i jego znaczenie w krajowej humanistyce będzie stopniowo wzrastało.

Równocześnie trzeba pamiętać, że naukowcy działający w polu groznawstwa reprezentują także inne dziedziny. Zgodnie z badaniami przeprowadzonymi przez zespół Fransa Mäyry ${ }^{57}$ tożsamość naukowa anglojęzycznych

56 S. Deterding The Pyrrhic victory of game studies..., s. 16-17.

57 T. Quandt, J. Van Looy, J. Vogelgesang, M. Elson, J.D. Ivory, M. Consalvo, F. Mäyrä Digital Games Research: A Survey Study on an Emerging Field and Its Prevalent Debates, "Journal of Communication" 2015 No. 6. 
badaczy gier jest złożona i rzadko mamy do czynienia z identyfikacją ograniczającą się do jednej dyscypliny. Podobnie polscy groznawcy to zarazem kulturoznawcy, filmoznawcy czy poloniści. W obrębie jednorodnej kultury epistemicznej, o której pisze Deterding, nadal jest zatem miejsce dla wielu różnych punktów widzenia. A jeśli nawet rozwój groznawstwa jako oddzielnej dyscypliny naukowej zostałby w Polsce zahamowany, wciąż prowadzone będą badania gier na gruncie innych dziedzin wiedzy.

\section{Abstract}

\section{Maria B. Garda}

UNIVERSITY OFŁÓDŹ

\section{Stanisław Krawczyk}

UNIVERSITY OF WARSAW

Twenty-Five Years of Digital Game Research in Poland

Krawczyk and Garda present the history of digital game research in Poland. Drawing on existing as well as newly generated data, they present early studies and later processes of institutionalization and internationalization. This, along with a discussion of the terminology, leads them to conclude that over the last few years Polish game research has given rise to the field of game studies, which is in many respects analogous to the respective fields in English-language academia. Additional arguments to support this thesis come from a quantitative analysis of articles published in Polish academic journals from 1995 to 2015. The discussion bears on the history of game research in Poland, the Nordic states and the USA.

\section{Keywords}

game research, game studies, groznawstwo, ludologia, ludology 